\title{
RESEÑA DE LIBRO LA EDUCACIÓN EN COSTA RICA. DE LA ÉPOCA COLONIAL AL PRESENTE, DE IVÁN MOLINA JIMÉNEZ
}

Palabras clave: reseña bibliográfica, educación, historia, Costa Rica, Iván Molina Jiménez.

Keywords: book reviews, educaction, historia, Costa Rica, Iván Molina Jiménez.

A riesgo de parecer injusto, es posible asegurar que existen cuatro grandes tradiciones en el estudio de la historia de la educación del país. Una primera aproximación sería la desarrollada de manera empírica a inicios del siglo XX por Luis Felipe González Flores. ${ }^{1}$ Impulsado por un apetito feroz por documentar el desarrollo y la cronología de la "evolución" de la instrucción pública, González Flores rastreó los archivos en busca de todo documento que pudiera dar cuenta de aquella problemática, teniendo como horizonte la larga duración. Sin duda, ese investigador se convirtió en el mayor conocedor de la historia de la educación del país durante buena parte del siglo XX y su aporte ha sido fundamental para cualquier otra persona que haya querido enfrascarse directa o indirectamente con ese tema.

1 Principalmente me refiero al libro: Luis Felipe González Flores, Evolución de la instrucción pública en Costa Rica (San José, Costa Rica: Editorial Costa Rica, 1978).

Fecha de recepción: 09/03/2017 - Fecha de aceptación: 17/04/2017

* Costarricense. Ph.D. en Historia por Indiana University, Bloomington, Indiana, Estados Unidos. Profesor catedrático en la Universidad de Costa Rica (UCR) y director del Centro de Investigaciones Históricas de América Central (CIHAC) de esa misma casa de estudios. Correo electrónico: DAVID. DIAZ@ucr.ac.cr 
A finales de la década de 1970, Carlos Monge Alfaro y Francisco Rivas Ríos le dieron forma a una segunda aproximación a la historia de la educación en el país, al construir un ensayo que interpretaba aquella historia en relación directa con el desarrollo de la democracia costarricense. ${ }^{2}$ Sin el conocimiento de fuentes de la experiencia de González Flores, pero con un sentido analítico más demarcado, la tesis fundamental de Monge Alfaro y Rivas Ríos, grosso modo, era que la democracia costarricense fue la consecuencia directa del avance del sistema educativo.

La tercera vía de análisis de la historia de la educación la desarrollaría la historiadora Astrid Fischel durante las décadas de 1980 y $1990 .{ }^{3}$ Con un instrumental teórico sumamente rico y con una imaginación investigativa acuerpada por multiplicidad de fuentes, Fischel le dio un carácter novedoso y remozado a los estudios sobre la historia de la instrucción. Esta investigadora planteó una serie de preguntas que la llevaban a identificar períodos, actores y coyunturas determinantes en su tema de estudio y a advertir diferencias, reformas y contradicciones. Ni empecinada positivista, ni impulsora de ensayos interpretativos, Fischel creó una obra de historia social y estructural de la educación que haría mella en ese campo de estudios.

En la década de 1990 y a inicios del siglo XXI aparecieron más trabajos, ahora de corte más culturalista y liderados por Iván Molina Jiménez y Steven Palmer, que impulsaron una cuarta forma de estudiar la educación. ${ }^{4}$ Evidentemente, todas esas tradiciones han tenido más colaboradores, continuadores, críticos e investigadores que las ampliaron o enfrentaron, pero seguramente en ellas se resumen todos esos esfuerzos.

El monumental libro de Iván Molina Jiménez ${ }^{5}$ sobre historia de la educación en Costa Rica viene a beber de aquellas cuatro tradiciones y, al leerlas, cuestionarlas, integrarlas y abordar nuevas fuentes y nuevos períodos, y proponer nuevas preguntas, ha producido una quinta forma de acercamiento a esta problemática tan fundamental para entender el país. ¿Es la definitiva?

2 Carlos Monge Alfaro y Francisco Rivas Ríos, La educación, fragua de nuestra democracia (San José, Costa Rica: EUCR), 1978.

3 Fischel hizo múltiples contribuciones. Aquí es importante subrayar: Astrid Fischel, Consenso y represión. Una interpretación socio-politica de la educación costarricense (San José, Costa Rica: Editorial Costa Rica, 1987) y Astrid Fischel, El uso ingenioso de la ideología en Costa Rica (San José, Costa Rica: EUNED, 1992).

4 Iván Molina Jiménez y Steven Palmer, Educando a Costa Rica. Alfabetización popular, formación docente y género (1880-1950) (San José, Costa Rica: EUNED, 2003).

5 Iván Molina Jiménez, La educación en Costa Rica. De la época colonial al presente (San José, Costa Rica: EDUPUC, 2016). 


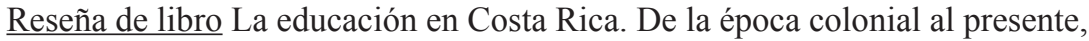
de Iván Molina Jiménez

Esta obra abarca un período de tiempo que explora cinco siglos - va de 1580 al 2016- y está dividida en dos grandes partes, cada una de ellas integrada por cinco capítulos.

El libro presenta en esos capítulos una serie de nuevas interpretaciones sobre la historia de la educación que son sostenidas por una impresionante cantidad de fuentes primarias que incluyen documentos de gobierno, memorias de educación, memorias de otras secretarías o ministerios del Estado, periódicos, informes, planes de educación, decretos, leyes, censos, estadísticas de educación, memorias personales, testimonios, presupuestos, folletos, boletines, anuarios estadísticos y literatura. Pareciera que Molina no dejó piedra sin levantar en busca de rastros sobre la educación en el país.

Además, la obra expone la más importante y completa reconstrucción de datos cuantitativos sobre el sistema educativo del país y presenta un erudito dominio de la bibliografía existente sobre la educación costarricense. Todo este arsenal blinda al texto y lo convierte en un libro robusto que aguanta las críticas y preguntas más disímiles y, por eso, se alza también como un trabajo enciclopédico al que se puede acudir con confianza en busca de grandes tesis, pero también de pequeños datos. Este libro, se podría resumir, inspecciona la producción, expansión, crisis y cuestionamiento del sistema educativo costarricense particularmente desde el siglo XIX hasta la actualidad. Es, por tanto, un libro indispensable para entender el país de ayer, pero principalmente el país de hoy en uno de sus principales pilares: la educación.

¿Cuáles son las principales tesis de esta obra?

Una primera y gran propuesta que aparece a lo largo del texto es la que cuestiona la relación determinista planteada en el pasado por Monge Alfaro y Rivas Ríos. En lugar de mirar la educación como impulsora de la democracia, Molina propone que fue la creciente demanda de la población costarricense por educación, la que se convirtió en el motor de impulso de esta. Para este autor, la educación es un campo de poder en donde se pueden medir tensiones surgidas desde los padres de familia y desde las comunidades y que se extienden hasta las principales esferas del gobierno.

De acuerdo con él, el principal rasgo del sistema educativo costarricense ha sido la condición pública de la primaria, asentada por la Constitución de 1869 y afirmada por la reforma educativa de mediados de la década de 1880. En ese marco, afirma Molina, "las presiones de las comunidades urbanas y rurales por más y mejor instrucción para sus niños y jóvenes, desde antes de la transición a la democracia ocurrida en el periodo 1889-1902, fueron fundamentales para promover esa índole estatal, consolidada una vez que la política empezó a estar dominada por una competencia electoral periódica, que facilitó una conexión estratégica entre las demandas de la ciudadanía, 
los compromisos de los partidos y la gestión del Estado". ${ }^{6}$ Esa presión de las familias y comunidades por educación se volvió un eje central del sistema de expansión de la educación primaria; así, la población costarricense, muy tempranamente, asumió la educación como un derecho que podían demandar del Estado. Molina concluye que "las condiciones económicas, sociales e institucionales que favorecían la democratización del país... fueron las que propiciaron también la expansión sostenida de la enseñanza, decisivamente impulsada por las gestiones de las comunidades urbanas y rurales por lograr la apertura de más escuelas públicas. La política democrática, que se configuró entre finales del siglo XIX y comienzos del XX, posibilitó que la conexión entre esas demandas ciudadanas y la competencia electoral se consolidara...".?

La educación como campo de poder se expresa también en otra gran tesis que propone Molina al revisar la reacción de las comunidades y familias a la reforma educativa de la década de 1880 . Tradicionalmente, todas las interpretaciones que se han hecho sobre aquel conflicto han indicado que las clases populares se oponían a la reforma liberal fundamentalmente por ignorancia y por obediencia a la Iglesia católica. Molina propone otra lectura; primero, indica que el crecimiento en el acceso a la educación en la segunda mitad del siglo XIX producía un primer conflicto al interior de las familias, por efecto de los niños que se alfabetizaban y ganaban capital cultural frente a sus padres. No obstante, ese enfrentamiento generacional, en alguna manera, era sopesado por la presencia de una educación religiosa que enfatizaba en imágenes y alentaba jerarquías que reproducían el orden. La secularización de la educación en la década de 1880 rompió con esa estructura y supuso un crecimiento en el nivel de tensión entre padres e hijos. De esa forma, la reforma educativa promovió un enfrentamiento generacional al interior de las familias que fue determinante en la manera en que los padres evaluaron e inmediatamente se opusieron a aquel proceso. Según Molina, su evidencia sugiere que "el rechazo a la reforma fue parcial y de índole política y cultural, y no expresión de una supuesta ignorancia de los sectores populares". ${ }^{8}$ Esta tesis devuelve el sentido de "agencia" histórica a aquellas comunidades, pero también trata de entenderlas en sus mentalidades, intentando así superar la visión misma que desde el presente en que escribían tenían los investigadores a la hora de evaluar la oposición a la reforma educativa liberal. Hay en eso una lección metodológica importante de subrayar.

6 Molina Jiménez, La educación en Costa Rica ..., 588.

7 Ibid, 597.

8 Ibid, 153. 
El siglo XX y la ampliación de la educación básica gratuita y obligatoria hasta noveno año de secundaria -1973-, a pesar de la presión que impuso sobre las familias rurales que apenas lograban asumir la obligatoriedad de enviar a sus hijos a la escuela hasta sexto grado, ${ }^{9}$ hizo que aquel conflicto cultural del siglo XIX quedara brevemente zanjado, pero no desaparecido. La secularización de la educación continuó siendo otro elemento para la disputa del poder, porque no menguaron los intentos de quienes presionaban por devolver la religión a los centros escolares, hasta que lograron reincorporarla a inicios de la década de 1940. A partir de ahí, pero con más potencia a fines del siglo XX y en las primeras décadas del siglo XXI, Molina encuentra una creciente influencia de la religión en el sistema educativo que incluso llegó hasta la universidad pública. ${ }^{10} \mathrm{~A}$ ese proceso se le opone con fuerza un grupo de académicos y estudiantes que apoyan la declaración de un Estado laico. No queda claro en el libro, a falta de datos, cuán representativo es ese nuevo grupo religioso o religiosamente orientado dentro de las universidades, ni si existen lazos entre él y el sector administrativo al interior de esos centros de estudio. El grupo más activista, el que impulsa la laicización, parece el más visible, pero esa es una lucha que no se da dentro de los centros de estudio, sino en la sociedad civil. Y en esa vía, esta batalla cultural; sin embargo, no parece conducir, por el momento, a una victoria de la secularización como ocurrió, por unas décadas, en el pasado. El libro, además, permite observar que esas conquistas, cuando se han dado, nunca son absolutas ni están resguardadas de cambios en la dirección contraria.

Molina advierte otro nivel de la disputa que refiere al enfrentamiento entre el pedagogismo que ganó cada vez más adeptos en la segunda mitad del siglo XX y aquel modelo de enseñanza que se había practicado con anterioridad y que le daba mayor énfasis al conocimiento científico del docente y a los contenidos de la materia que a su entrenamiento pedagógico. Molina toma un posicionamiento específico en este debate que no esconde, sino que subraya al considerar el resultado como uno de los principales problemas de la educación del país. Así, indica que el pedagogismo avanzó poderosamente en 1957, 1970 y 1973 y que en la Universidad de Costa Rica ese proceso se vio consolidado con la acción directa de la Escuela de Pedagogía al dominar la preparación de todos los estudiantes que estuvieran matriculados en carreras vinculadas con la docencia en primaria y secundaria. Según Molina, el principal resultado fue "que los futuros profesionales en estos campos quedaran adscritos a la

9 Ibid, 358.

$10 \mathrm{Ibid}, 576$. 
instancia institucional de menor competencia académica". ${ }^{11}$ La sentencia fue que cada vez más se relegó el conocimiento científico por el pedagógico y que eso se consolidó con la apertura de licenciaturas primero y maestrías después, que se orientaban en esa dirección. Esta es otra batalla en franco desarrollo. A la absoluta dominación del modelo pedagogista le ha sucedido un activismo dentro de los departamentos y escuelas donde se cultivan los conocimientos científicos y que aspira a desmonopolizar a las facultades de educación públicas de su dominio sobre el contenido principal de las carreras docentes. ¿Lo lograrán? Ojalá. No obstante, ni siquiera un cambio drástico en esa vía al interior de las universidades públicas podrá realizar grandes transformaciones nacionales, puesto que, como lo documenta Molina, la formación de docentes, desde hace años, está dominada por las universidades privadas.

La situación indicada tuvo serias consecuencias para la educación costarricense que Molina explora en detalle en los últimos capítulos de su libro. Valdría la pena subrayar que uno de esos resultados fue el deterioro de la imagen del docente mismo. En el campo profesional, la docencia en primaria y secundaria fue vista por encima del hombro por otros profesionales que incluso construían estereotipos de los maestros como malos profesionales. Además, Molina encuentra un contraste en la forma en que las comunidades y familias conceptuaban a los docentes a inicios de la segunda mitad del siglo XX y cómo lo hacían a finales de esa centuria. Del maestro respetado se pasó al docente ignorado o enfrentado y del que incluso se hacían bromas. En ese deterioro, Molina advierte, no ayudaron los sindicatos docentes que en lugar de tomar posición y promover un mayor conocimiento de las ciencias que enseñaban sus afiliados, se enfrentaron y enfrentan a cualquier intento por evaluarlos con base en conocimientos de sus materias y condicionar su contratación o incentivos salariales a partir de esa evaluación.

Al ofrecer datos presupuestarios desgranados por años, Molina prueba que la educación costarricense experimentó dos grandes crisis durante el siglo XX. La primera se produjo durante la dictadura de Federico Tinoco (1917-1919) cuando aumentó el presupuesto militar frente al educativo y la segunda ocurrió por efecto de la grave crisis económica que envolvió a Costa Rica entre 1980 y 1982. Aquí Molina lanza otra bomba, esta vez vinculada con la conceptualización de los gobiernos del Partido Liberación Nacional, al indicar que fue hasta en el segundo gobierno de Óscar Arias Sánchez (20062010) cuando el sistema educativo se logró recuperar de la crisis de inicios de la década de 1980. Esta afirmación, desde luego, no deslegitima los cuestionamientos desarrollados por intelectuales, académicos o la sociedad civil a la forma en que se manejó el Estado a finales del siglo XX y principios del XXI,

$11 \mathrm{Ibid}, 419$. 
ni a los casos de corrupción asociados con esos gobiernos. Al respecto, sería interesante seguirle la pista a la manera en que los candidatos de ese período plantearon el tema de la educación en sus programas de gobierno. No hay duda de que la educación pública se plantea siempre como un tema central en los debates políticos, pero pareciera que esa discusión ha estado cada vez más mediada por la creciente influencia de los grupos religiosos con poder político y de las ofertas "populistas" que proponen reformas con cierto impacto electoral-eliminar las pruebas de bachillerato, por ejemplo-.

El texto de Molina constituye, sin ninguna duda, el mayor aporte que se haya realizado al entendimiento de la educación del país. No solo explora todos los niveles educativos en perspectiva histórica, sino que integra al análisis los centros privados, la educación religiosa, la experiencia por género y etnia, el mundo de los docentes y de los estudiantes, el papel de los empresarios, las reformas, las personas que influyeron en la toma de decisiones sobre la educación, las propuestas que se descartaron y las que se asumieron, los salarios docentes y otro cúmulo de problemáticas.

Al demarcarse en la larga duración, el libro mira con cuidado procesos que se originaron en el siglo XIX y que han experimentado considerables cambios o continuidades hasta hoy. Actualizado en su bibliografía y en su perspectiva analítica, el trabajo de Molina no solo permite advertir los principales debates nacionales e internacionales sobre la educación, sino que da herramientas y abre temas que sería fundamental explorar con detenimiento en el futuro cercano.

Este es un trabajo de lectura obligatoria, pero que también precisa que se lea a la par de otro gran texto del mismo autor: Demoperfectocracia. ${ }^{12}$ Con esos dos estudios, cualquier investigador, docente, estudiante o interesad en la historia del país, podrá entender la construcción de la Costa Rica moderna en dos de sus principales pilares: la educación y la lucha electoral.

No está por demás cerrar este comentario indicando que la calidad del libro reseñado fue reconocida por el jurado del Premio Nacional a la Investigación Cultural "Luis Ferrero", que le concedió ese galardón al trabajo de Molina en el 2016. Un premio muy merecido que coloca el listón de ese reconocimiento en lo más alto, donde debe estar siempre.

12 Iván Molina Jiménez, Demoperfectocracia. La democracia pre-reformada en Costa Rica (1885-1948) (Heredia, Costa Rica: EUNA, 2005). 